enter. Now the herd, whose counting ability is very limited, will at once detect whether one or more animals are missing, and will give an absolutely correct description of the colour, markings, and physical peculiarities of the missing beasts. It is the most astonishing performance I have seen.

Steatopygia is general amongst the Hottentots and not among the true Bushmen. Almost all the women of the former race exhibit in a greater or less state of development the fatty enlargement of the buttocks and hips. This form of steatopygia is often enormous, as depicted in the illustration to your article, but the feature which is perhaps more noticeable than the size is the quaking and shivering motion of the fatty masses caused by the movement of the woman when walking. It is for all the world as if the buttocks were composed of quivering jelly and a good specimen case once seen is never forgotten. These enormous buttocks, however, seem to have their use, for they make admirable supports with the aid of a skin shawl whereon to carry the younger children when the mother is trekking. I have really seen children being thus carried literally looking over the edge.

The condition of skin extending over the pubes and alluded to in your article is caused by a continual pulling and stretching of, generally, the vaginal labia and clitoris from very early childhood, causing a great deal of extra growth which falls as a flap and well covers the vagina. This growth is calls the lappell, but what is its actual use I could not find out. All the Hottentot women have it. One woman tried to explain the use of the lappell in this way: "You know that the Hottentot women always squat on their haunches around the fire, and the wood fire is dusty, and the ground is dusty; well, the good God has given us the lappell to keep the dust out."

The Hottentots have always lived in communities with a recognised head-man or captain. The men are excellent fighters, wonderfully fine scouts, and are absolute masters in their instinctive art of spoor finding or tracking, but, unfortnnately, owing to their excessively drunken and pilfering habits they figure largely in the law courts. I am, Sir, yours faithfully,

HeRBERT D. CROOK, M.R.O.S. Eng., L.R.C.P. Edin. Southstoke, Bath, Jan. 30th, 1909.

\section{PURULENT CONJUNCTIVITIS OF INFANCY.} To the Editor of THE LANCET.

Sir,-Mr. Percy Dunn's letter in The LANCET of Feb. 6th, p. 426, on the terminology of what he calls the " purulent conjunctivitis of infancy" is interesting, although I for one cannot agree with him in thinking that to change the timehonoured name "ophthalmia neonatorum " to the one favoured by himself would help us much. To my mind, indeed, there does not appear to be a great deal to pick between them, since one is as uncouth as the other and both are more or less inexact. Newly born children suffer from inflammations of the eye other than ophthalmia and every conjunctivitis in newly born children is not purulent. But, after all, it is the disease, which is still by far the commonest cause of blindness in children, and not the name that matters. If by a simple change from one name to the other good can be done, then let us change it forthwith. The committee on ophthalmia neonatorum of the British Medical Assocation, I am confident, will be only too glad to hear of practical proposals for the extirpation of the malady itself (call it what you will), the very existence of which constitutes a standing reproach to those who have to care for parturient women. The committee, I may add, is a strong one, including, as it does, representatives of the British Medical Association, the Obstetrical and Gynæcological Section of the Royal Society of Medicine, the Ophthalmological Society, the Section for the Study of Disease in Children of the Royal Society of Medicine, and, last but not least, the Society of Medical Officers of Health. Now is the time for all who are interested in this unhappy disease to be up and doing. Deeds are wanted more than words, whether they be applied rightly or wrongly.

\section{I am, Sir, yours faithfully,}

\section{SYDNEY STEPHENSON}

Chairman of the Committee on Ophthalmia Neonatorum of the British Medical Association.

Welbeck-street, W., Feb. 8th, 1909 .

\section{THE TREATMENT OF SCHOOL CHILDREN} BY THEIR TEACHER.

\section{To the Editor of THE LANCET.}

SrR, -A few days ago a woman came to consult me about her child, a little girl, who had a sore on her chin. She told me the following story. The previous morning she noticed a red patch on the child's chin, and thinking it was possibly ringworm kept the child from school and wrote to the teacher telling her the reason. She got an immediate reply telling her to send the child. On her arrival at the school -one under the London County Council - she was examined by the teacher who took some fluid out of a bottle on a slate pencil and applied it to the patch. Next morning the chin appeared worse, and also remarking a swelling in the neck the mother brought the child to me. This story so surprised me that I wrote to the teacher asking her if the school medical officer had seen the child, or if she had treated her, and if so what had she applied. After receiving my letter the teacher called on me and told me no medical officer had seen the child, but she knew the child had ringworm and had treated it with pure sulphurous acid. It has always been her custom to do so in these cases and the only ones she does not treat are ringworm of the scalp. She is positive she can diagnose ringworm, always treats it as above, has never failed to cure, and never done any harm.

These facts raise two interesting points: 1. Are school teachers, when informed by parents that a child is possibly suffering from ringworm, correct in ordering the child to be sent to school without having it first examined by a medical man? 2. Is it customary or allowable for teachers under the London County Council to treat cases of ringworm or other skin diseases with applications such as sulphurous acid without medical instruction or control?

I am, Sir, yours faithfully, - K. R. Collis HaLlowes.

Bucklngham Palace-road, s.W., Feb. 5th, 1909.

\section{THE TREATMENT OF SYPHILIS.}

\section{To the Editor of THE LANCET.}

SrR,-I notice in your issue of Feb. 6th, p. 426, a letter from Mr. T. P. Beddoes drawing attention to a slight inaccuracy of expression in Dr. Stopford Taylor's "Note on the Treatment of Syphilis." As the formula for grey oil is a somewhat complicated one Dr. Taylor asked me some time ago to calculate accurately for him the amount of mercury administered in each dose, and I believe I am responsible for the error. Dr. Taylor says in his note, "Barthelemy's syringe is graduated in centigrammes, a complete syringeful holding in all 14 centigrammes, this amount of grey oil containing two and a half grains of metallic mercury by weight." Now, as $\mathrm{Mr}$. Beddoes points out, this would make the dose of mercury in each syringeful 40 per cent. of 14 centigrammes, that is, $5 \cdot 6$ centigrammes, or a little over three-quarters of a grain.

Barthelemy's syringe does not, however, contain one centigramme of grey oil in each division, but is graduated in such a manner that when used with a 40 per cent. grey oil one centigramme of metallic mercury is contained in each of its divisions, and as Dr. Taylor states 14 centigrammes of metallic mercury or approximately two and a half grains in each syringeful. The syringe, which has a capacity of about five minims, is thus graduated not in centigrammes of grey oil but in centigrammes of mercury and when full contains 35 centigrammes of grey oil, 14 of which is metallic mercury. Grey oil is made up to contain 40 per cent. of metallic mercury by weight, using as excipient a mixture of liquid paraffin and vaseline. Now, the compounding of a mixture by weight, which is to be afterwards measured for administration by volume, is unscientific and though quite admissible where water is the excipient may lead to serious error where an exeipient is used which is not of a definite and constant density.

Liquid paraffin according to the American Pharmacopceia varies in density in different specimens between 0.87 and 0.94 -that is, a range of variation of approximately 7 per cent. Let us suppose that the makers of the syringe regulate the contents of each division so that it shall contain one centigramme of metallic mercury when used with grey oil made up with a paraffin with a density of $0 \cdot 37$. It may 
happen that when the syringe comes to be used the grey oil employed may be made with a paraffin of density 0.94 , and 35 centigrammes of this oil will occupy a smaller volume than the same weight of the oil for which the syringe was originally graduated. Hence, if the syringe be filled with this heavier oil a dose of mercury about 7 per cent. larger than was intended will be administered. This is not perhaps a large or serious inaccuracy but it could be avoided by mixing the mercury during the process of the manufacture of the oil, not with a measured weight of paraffin, but with a measured volume. The same volume of various specimens of grey oil made up in this way would then contain always the same amount of mercury, no matter what the density of the paraffin employed might be.

With a grey oil made up in this way it would not be necessary to have the specially graduated syringe which is required for an oil made up by weight, for it would be a simple matter to calculate the volume of oil which would contain the exact dose of mercury required and any syringe graduated in cubic centimetres or in minims could be employed.

I am, Sir, yours faithfully,

Liverpool, Feb. 8th, 1909. WAITER C. ORAM, M.D. Dub.

\section{REPATR OF PERFORATIONS DURING THE SUBMUCOUS RESECTION OPERATION.}

\section{To the Editor of THE LANCET.}

SIR,-It is interesting to note how the same idea will strike two persons in different parts of the world. The suggestion published in THE LANCET of Jan. 16th, p. 166, by Dr. F. D. Gulliver of New York occurred to and was put into practice by me with excellent result last November.

I am, Sir, yours faithfully,

MACLEOD YearsLey, F.R.C.S. Eng.

Harley•street, W., Feb. 3rd, 1909.

\section{THE TREATMENT OF' RHEUMATOID ARTHRITIS BY :INTESTINAL LAVAGE.}

To the Editor of THE LANCET.

SIR, - I have read with much interest Dr. F. Booth's article on this subject in THE LANCET of Dec. 19th, 1908, p. 1814. I have for the last eight years used this method in cases of rheumatoid arthritis with considerable success. Of course, it is only of value in a certain limited group in which the so-called joint centres in the cord are poisoned by toxins absorbed from the intestinal tract. The important point seems to be the selection of the proper cases for this form of treatment and my guide has been the appearance of a considerable excess of aromatic sulphates in the urine. Otservations of a considerable number of patients suffering from rheumatoid arthritis strongly support the view that the joint symptoms may depend upon one or more of a number of reflex sources of irritation. These have to be dealt with, while at the same time the nerve-supply to the joint has to be strengthened and any underlying gouty or rheumatic conditions dealt with. I have found various electrical methods, counter irritation to the spine and joints, "Salisbury meat dietary," and Metchnikoff's "sour milk" treatment powerful adjuncts to mineral waters and baths but the success depends almost entirely upon recognition of the exact form of the disease with which we have to deal. I am, Sir, yours faithfully,

Buxton, Feb. 4th, 1909. W. ARMSTRONG.

\section{THE PRESENT EPIDEMIC OF COMMON COLDS.}

To the Eatior of THE LANCET.

SIR,--In the paper upon "The Common Cold" which appeared in THE LANCEr of Nov. 28th and Dec. 5th of last year I stated that I thonght it quite likely that additional organisms might have to be added to the list therein contained as being productive of the common cold. A minute bacteriological examination of 50 cases of the epidemic raging during the past two months has shown that at least 90 per cent. of these have been due to the pneumococcus, either alone or complicated either by the M. catarrhalis or M. paratetragenus, or by both of these. In three out of the 50 cases the $B$. influenzæ was present, once alone, twice together with the pneumococcus. This pneumococcal cold is clearly differentiated from the other varieties. It would appear to begin with slight cough, located in the upper part of the trachea. This extends within two to three days both downwards into the bronchi and upwards into the larynz; later the bronchioles and naso-pharyngeal space are also involved. Malaise is pronounced, the temperature may rise to $102^{\circ}-103^{\circ} \mathrm{F}$., there may be slight frontal head. ache, the cough becomes very bad and may be pronouncedly paroxysmal, and the secretion of mucus, which is clear, viscid, and jelly-like at the beginning and later, perhaps, of a bright yellow colour, is very profuse. Hearing, taste, and smell may be very markedly impaired, the former from extension to the Eustachian tube, the latter from that to the turbinal bones. The inferior meatus of the nose may com. pletely escape involvement, with the curious result that, despite copious nasal secretion and pronounced engorgement of the mucosa of the nasal septum and that of the middle and superior turbinal bones, nasal respiration may be comparatively free. The subacute stage may be prolonged into several weeks, during which the nasal and bronchial secretion may continue very profuse and blood-stained and hearing, taste, and smell remain much impaired. The mixed infection by means of the M. catarrhalis and M. paratetragenus may complicate the clinical picture. Treatment upon general lines is rather unsatisfactory and the response to vaccine therapy not so prompt as in the other varieties of the " common cold." Due attention must, of course, be paid to the various organisms in the cases of mixed infection. The dose of pneumococcus should not exceed $50,000,000$ for a first injection, but may be combined with 50-75 millions of M. catarrhalis or M. paratetragenus. Ten days later a dose of double this amount may be safely given. In this way the duration of even a severe attack may be confined within 14 to 17 days or less.-I am, Sir, yours faithfully,
London, W., Feb. 2nd, 1909.
R. W. Allen, M.D. Lond.

\section{THE TREATMENT OF ULCERATIVE COLITIS.}

To the Editor of THE LANCET.

SIR,-When reading the interesting paper by Sir W. Allchin on Ulcerative Colitis reported in THE LANCET of Feb. 6th, p. 393, I noticed that in enumerating the methods of treatment of this disorder no mention is made of that by creosote dissolved in ol. morrhuæ. In this asylum we have had on many occasions considerable experience of severe cases of dysentery, and have tried at various times practically all the methods of treatment mentioned by Sir W. Allchin. We have, however, for some years past been so convinced of the superiority of the treatment by creosote and ol. morrhuæ that it is now exclusively made use of here. And I have no hesitation in saying that it relieves the symptoms more quickly and shortens the course of the disease more effectually than any other. I have not statistics by me just now, so cannot dogmatise about the relative mortality, but in my own opinion we have also had less mortality since adopting this method. The dose used here is as follows: Creosot. miii., ol. morrh. $3 \mathrm{i}$. is given three times daily on the first day of the disease, castor oil having been previously administered. This is increased by $3 \mathbf{i}$. daily until on the fourth day the patient is taking creosot. $m x$ xii., ol. morrh. $\xi$ ss. This is continued until the termination of the disorder. Trusting that this may prove of interest,--I am, Sir, yours faithfully,

Euwin L. Dunn, M.B. Dab., \&c.

Berksliire Asylum, Wallingford, Feb. 9th, 1909.

\section{AN UNFAIR IMPOSITION.}

\section{To the Editor of THE LANOET.}

SrR,- - Some years ago that astute statesman, the late Lord Selborne, in an interesting address to the students of King's College, while bearing grateful testimony to the great dignity of the medical profession, regretted that it possessed fewer attractions, in the shape of adequate rewards, as compared with the sister learned professions, to tempt a greater proportion of the higher intellects among the youth of the 